\title{
Monitoring Approach to Evaluate the Performances of a New Deposition Nozzle Solution for DED Systems
}

\author{
Federico Mazzucato ${ }^{1, *}$, Simona Tusacciu ${ }^{2}$, Manuel Lai ${ }^{2}$, Sara Biamino ${ }^{3}$, Mariangela Lombardi ${ }^{3}$ \\ and Anna Valente ${ }^{1}$ \\ 1 SUPSI, ISTePS-Institute of Systems and Technologies for the Sustainable Production, Galleria 2, \\ Manno (6928), Switzerland; anna.valente@supsi.ch \\ 2 IRIS S.r.l., Via Papa Giovanni Paolo II, 26, 10043 Orbassano, TO, Italy; simona.tusacciu@irissrl.org (S.T.); \\ manuel.lai@irissrl.org (M.L.) \\ 3 Department of Applied Science and Technology, Politecnico di Torino, Corso Duca degli Abruzzi, 24, \\ 10129 Torino, Italy; sara.biamino@polito.it (S.B.); mariangela.lombardi@polito.it (M.L.) \\ * Correspondence: federico.mazzucato@supsi.ch; Tel.: +41-(0)58-666-67-08
}

Academic Editors: Salvatore Brischetto, Paolo Maggiore and Carlo Giovanni Ferro Received: 18 April 2017; Accepted: 25 May 2017; Published: 31 May 2017

\begin{abstract}
In order to improve the process efficiency of a direct energy deposition (DED) system, closed loop control systems can be considered for monitoring the deposition and melting processes and adjusting the process parameters in real-time. In this paper, the monitoring of a new deposition nozzle solution for DED systems is approached through a simulation-experimental comparison. The shape of the powder flow at the exit of the nozzle outlet and the spread of the powder particles on the deposition plane are analyzed through 2D images of the powder flow obtained by monitoring the powder depositions with a high-speed camera. These experimental results are then compared with data obtained through a Computational Fluid Dynamics model. Preliminary tests are carried out by varying powder, carrier, and shielding mass flow, demonstrating that the last parameter has a significant influence on the powder distribution and powder flow geometry.
\end{abstract}

Keywords: direct deposition machine; scanner systems; metallic additive manufacturing

\section{Introduction}

In recent years, additive manufacturing (AM) technologies for the production of metal parts have drawn an enormous surge of industrial interest; however, process reliability and component quality are not enough for mass production [1]. In opposition to systems able to selectively melt a powder bed, high build rates and larger part volumes can be obtained by exploiting direct energy deposition (DED) technologies [2,3]. In this technology, previously trademarked as laser engineered net shaping (LENS), laser metal deposition (LMD), or direct metal deposition (DMD), a heat source generates a melt pool on a metallic surface into which feedstock is deposited with the consequent building of the parts layer by layer. At the moment, several solutions are available, using wire or powder as feedstock; in former versions, the processes could be considered a type of welding technology, whereas the latter ones are very similar to laser cladding technologies.

In view of the introduction of AM machines to the industrial world, it is necessary to study and develop monitoring and control systems capable of guaranteeing series production capability and reproducibility of these innovative processes. For this reason, recent AM technology reviews have repeatedly called for real-time, closed loop process controls and sensors to ensure quality, consistency, and reproducibility across AM machines [4].

DED systems employing powder feeding are highly sensitive to working conditions; any variation of process parameters during the deposition and melting of the metal powders can influence the quality 
of the component, compromising the process efficiency [5]. In particular, the deposition quality can be affected by intrinsic parameters (related to the properties of the substrate and the metallic powder such as geometry, thermal diffusivity, absorptivity, thermal conductivity, and heat capacity) and extrinsic parameters (related to the laser, the powder feeder, and the positioning system). In particular, extrinsic parameters are strictly related to the specific print head of the employed AM machine, in which powder injection nozzles and the laser beam are assembled according different schemes [6]. Indeed, common DED or cladding powder injection systems can present:

- an off-axis configuration, in which a single powder flow laterally passes through the laser beam;

- a continuous coaxial configuration, in which a conical powder flow surrounds and interacts with the laser beam;

- a discontinuous coaxial configuration, with several powder flows from different injection nozzles (i.e., multiple nozzle deposition) distributed around the laser beam (up to eight in a robotized laser-based direct metal deposition system recently developed [7]).

The off-axis powder injection implies a strong relation between the deposition rate and the scan direction [8]; in the continuous coaxial version, as opposed to the discontinuous axial one, the tilting of the powder injection nozzle is restricted, limiting the potentialities of DED [6]. Multiple nozzle deposition is suitable for parts with high geometrical complexity, even if it is more difficult to ensure flow uniformity and direct the powder to a specific region of interest [9]. In the case of both continuous coaxial configuration and discontinuous coaxial configuration, the spot of the powder flow in correspondence with the deposition plane usually ranges between $5 \mathrm{~mm}$ and $8 \mathrm{~mm}[6,10-13]$.

As already stated, the process efficiency can be influenced by the design of the powder injection nozzle, since it is capable of modifying interactions among the metallic particles, laser beam, and melt pool [14]. Further, the control of extrinsic parameters can be useful for adjusting deposition errors during the process. For this reason, in order to improve the process reliability and quality, closed loop control systems should be introduced in DED machines [15]. Indeed, in closed loop control, it is possible to exploit different devices to monitor the deposition and melting processes, by using the recorded data as feedback to setup the optimal process parameters.

In this paper, the first part of a larger research project is presented, in view to design a tailored deposition closed loop control to improve the performances of DED systems, guaranteeing their maximum efficiency during the process. In particular, this preliminary study is focused on the performances of a double chamber nozzle solution, controlled through the evaluation of the shape of the powder flow at the exit of the nozzle outlet and the spread of the powder particles on the deposition plane. During experimental tests, the powder flow is monitored with a high-speed camera, in order to confirm its simulating behavior obtained through a Computational Fluid Dynamics CFD model $[16,17]$. The experimental tests demonstrate that, in the analyzed configurations, the shielding gas seems to have a significant influence on the powder distribution and powder flow geometry.

\section{Materials and Methods}

A new deposition nozzle solution for DED is designed at the Department of Innovative Technologies (DTI) of University of Applied Sciences and Arts of Southern Switzerland (SUPSI), Manno-CH (see Figure 1a). It consists of a hybrid solution of continuous and discontinuous coaxial systems, with a double chamber coaxial nozzle (see Figure 1b), where the central powder-gas flow is shielded by an external annular flux of inert gas in order to prevent the oxidation of the melt pool, even in the case of no-hermetic deposition chamber, and to improve the catchment efficiency during the deposition, limiting the spread of the powder flow coming out from the nozzle outlet. Two deposition nozzles with an inclination of $30^{\circ}$ are placed in a testing chamber employed to characterize the powder flow coming out from the nozzle outlets (see Figure 2a). The deposition nozzles are connected with a flexible feeding system so that the control of shielding, carrier, and powder mass flow can be independent and precise (see Figure 2b). 


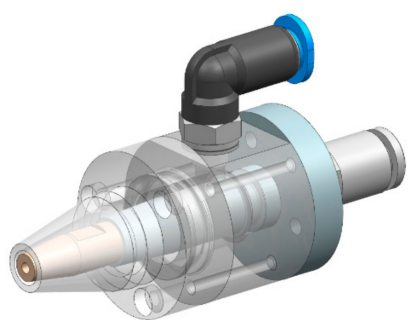

(a)

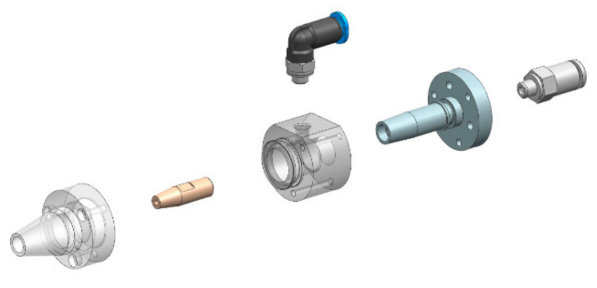

(b)

Figure 1. (a) New nozzle solution assembly; (b) exploded diagram of the nozzle.

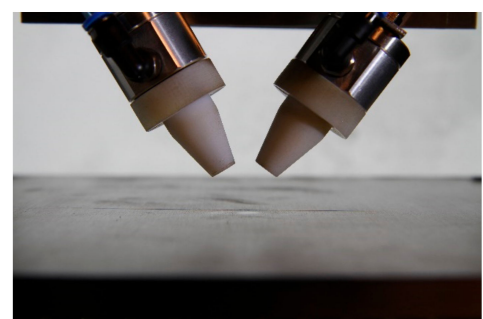

(a)

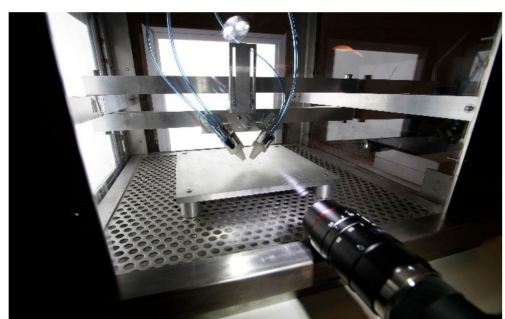

(b)

Figure 2. (a) Deposition nozzle configuration; (b) custom feeding system demonstrator at SUPSI.

In order to investigate the performances of the new nozzle solution, an experimental campaign is carried out to analyse the powder spread at $15 \mathrm{~mm}$ from the nozzle outlet (i.e., the location of the deposition plane). The chosen carrier and shielding inert gas is argon. The metal powder employed during this experimental investigation is a gas atomized Ti-6Al-4V powder (EOS GmbH-Electro Optical Systems) with a particle size distribution ranging between $45 \mu \mathrm{m}$ and $105 \mu \mathrm{m}\left(\mathrm{d}_{50}: 70 \pm 5 \mu \mathrm{m}\right.$, as mentioned by the powder supplier).

As shown in Figure 3, in order to evaluate the performance of the nozzle solution, three different process conditions are considered:

- $\quad$ in the first one, only one nozzle is active without the presence of the substrate (see Figure 3a);

- $\quad$ in the second one, two nozzles are active without the presence of the substrate (see Figure 3b);

- $\quad$ in the third one, two nozzles and a flat substrate placed at $15 \mathrm{~mm}$ from the centre of the nozzle outlet are present. In this case, a flat substrate is included in order to analyse the effectiveness of the provided nozzle solution in limiting the spread of the powder particles at the first layer deposition (see Figure 3c).

In particular, experimental tests are carried out with various carrier, shielding, and powder mass flow rates applying a full factorial $2 \times 3 \times 2$ design, according to the Design of Experiments (DOE) approach, as listed in Table 1. Each value range is fixed starting from process parameters commonly adopted in DED [9]. The experimental results are investigated, taking into account a confidence interval of $95 \%$ and running three repetitions for each parameter setting.

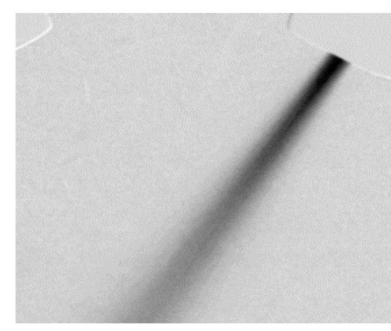

(a)

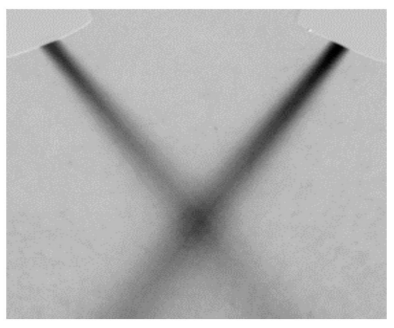

(b)

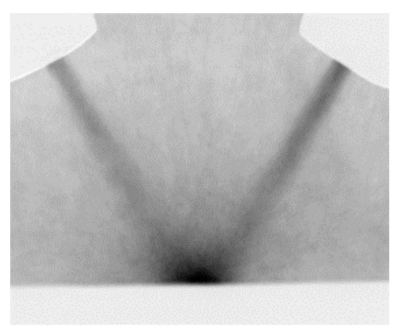

(c)

Figure 3. (a) One active nozzle; (b) two active nozzles; (c) two active nozzles with a substrate at $15 \mathrm{~mm}$. 
Table 1. Evaluated experimental factors.

\begin{tabular}{cccc}
\hline Process Parameters for One Nozzle & Low level & Medium level & High level \\
\hline carrier mass flow rate $(\mathrm{kg} / \mathrm{s})$ & $4.51 \mathrm{e}^{-0.5}$ & & $5.41 \mathrm{e}^{-0.5}$ \\
shielding flow rate $(\mathrm{kg} / \mathrm{s})$ & 0 & $1.95 \mathrm{e}^{-0.4}$ & $2.92 \mathrm{e}^{-0.4}$ \\
powder feed rate $(\mathrm{g} / \mathrm{s})$ & 0.1 & & 0.14 \\
\hline
\end{tabular}

A high-speed acquisition camera records the variation of the powder flow for every combination of process parameters, and the shape and width variation of the powder flow is detected and measured through image analyses performed with the open software ImageJ [18] (see Figure 4).

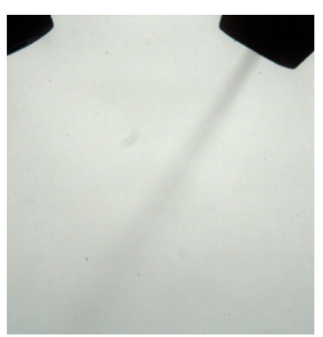

(a)

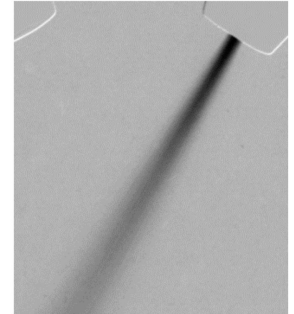

(b)

Reference line of the centre of the nozzle outlet

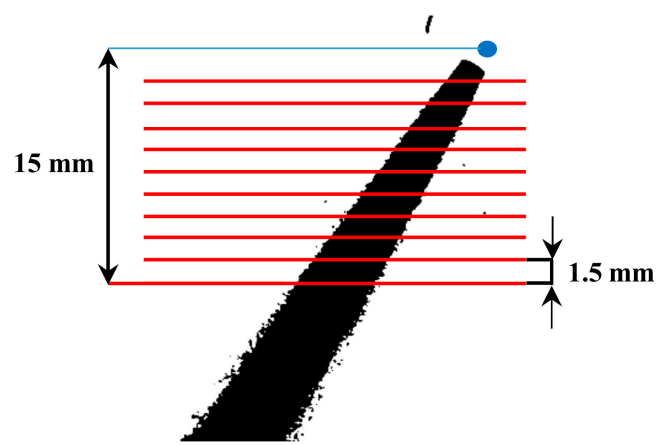

(c)

Figure 4. (a) Acquired image; (b) acquired image after subtracting the background; (c) evaluation planes on the image filtered by "binary-mask".

To correctly analyse the powder flow profile, reducing the presence of undesired floating particles which can deteriorate and worsen the powder flow characterization, 10 images are extracted from each experimental video and subsequently averaged (see Figure 4a). From the resulting image, the corresponding background is subtracted (see Figure $4 \mathrm{~b}$ ) and a "binary-mask" filter is applied to highlight the contour and the shape of the powder flow (see Figure 4c). To characterize the width variation of the powder flow along its extension, 10 equally spaced evaluation planes are traced below the nozzle outlet (i.e., the red lines in Figure 4c). The 95\% of the portion of plane crossing the powder flow is taken into account as the local width of the powder flow, cutting the total powder flow intensity in correspondence to the analysed evaluation plane of $2.5 \%$ at its beginning and end. This is required due to the irregular shape of the powder flow along its edges.

The binary-mask filter converts an image in black and white thanks to the preliminary definition of an intensity threshold. This tool is very useful in image processing, nevertheless, in this case, the choice of an intensity threshold is critical since it directly affects the size and extension of the powder flow (see Figure 5a,b). To objectively determine this value, an iterative method is designed, forcing an equal total intensity of the powder flow through the last five evaluation planes (see Figure 6). The purpose of this constraint is to suppose an equal quantity of powder particles passing through the 
evaluation plane for an equal value of total intensity in correspondence with each plane. The equation employed in this case is listed below:

$$
\frac{\sum_{k=1}^{5} I_{k}}{5}-\left(\frac{\sum_{k=1}^{5} I_{k}}{5}\right) 5 \%<I_{k}<\frac{\sum_{k=1}^{5} I_{k}}{5}+\left(\frac{\sum_{k=1}^{5} I_{k}}{5}\right) 5 \% \forall \mathrm{i}=1, \ldots, 5
$$

where $I_{k}$ is the corresponding total intensity of the powder flow for each evaluated plane. For each experimental video, the intensity thresholds chosen for the binary-mask filter are those satisfying Equation (1) (see Figure 6).

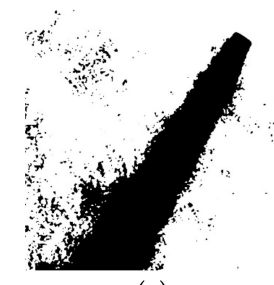

(a)

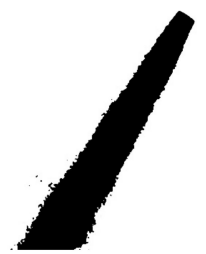

(b)

Figure 5. Binary-mask filter: resulting powder flow for different intensity thresholds (carrier $=4.51 \mathrm{e}^{-0.5} \mathrm{~kg} / \mathrm{s}$; shielding $=2.92 \mathrm{e}^{-0.4} \mathrm{~kg} / \mathrm{s}$; powder feed rate $=0.14 \mathrm{~g} / \mathrm{s}$ ): (a) intensity threshold of 206; (b) intensity threshold of 198.

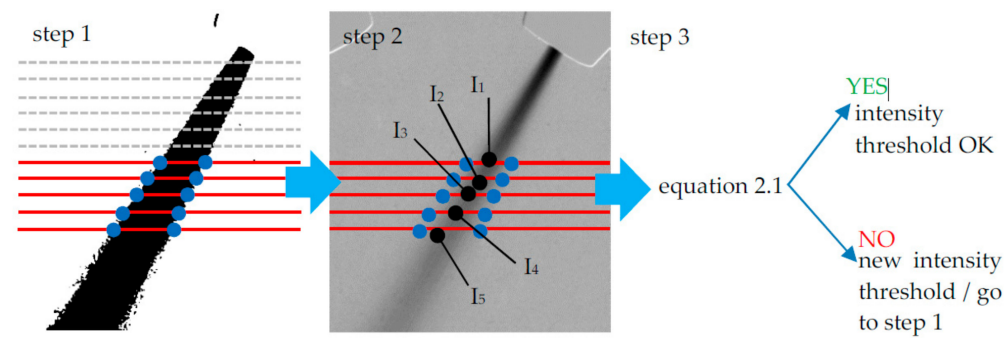

Figure 6. Scheme of the iterative method employed to determine the intensity threshold.

\section{CFD Modeling and Theoretical Assumptions}

The deposition simulation is approached by using CFD analysis, as generally occurs for DED processes, modelling particle powders as a discrete phase dispersed into a continuous phase (i.e., the inert gas). This approach is widely employed in the scientific literature to simulate fluid-dynamics problems when a low volume fraction of powder particles is dispersed and dragged by a gas. Carrier and shielding gases are computed as a continuous phase applying the standard $k-\varepsilon$ turbulent flow model available in ANSYS ${ }^{\circledR}$ FLUENT (v15.0) and based on the Navier-Stokes equations. To describe a turbulent flow, the time-averaging governing equations are:

- conservation of mass:

$$
\frac{\partial}{\partial x}\left(\rho u_{i}\right)=0
$$

where $\rho$ is the argon density $\left(1.623 \mathrm{~kg} / \mathrm{m}^{3}\right), u_{i}$ is the gas velocity, and $x_{i}$ is the gas position.

- Conservation of momentum:

$$
\frac{\partial}{\partial x}\left(\rho u_{i} u_{j}\right)=-\frac{\partial p}{\partial x_{i}}+\frac{\partial\left(\left[\left(\mu+\mu_{t}\right)\left(\frac{\partial u_{i}}{\partial x_{j}}+\frac{\partial u_{j}}{\partial x_{i}}\right)\right]\right)}{\partial x_{j}}+\rho g_{i}
$$

where $p$ is the pressure, $g$ is the gravitational acceleration, $\mu$ is the molecular viscosity $\left(2.125 \times 10^{-5} \mathrm{~kg} / \mathrm{m} \mathrm{s}\right)$, and $\mu_{t}$ is the turbulent viscosity. 
The most commonly used model to handle this situation is the standard $k-\varepsilon$ model, in which $k$ and $\varepsilon$ represent the turbulent kinetic energy and the dissipation of kinetic energy respectively. The conservation of the kinetic energy of turbulence is given by:

$$
\frac{\partial\left(\rho k u_{i}\right)}{\partial x_{i}}=\frac{\partial\left[\left(\mu+\frac{\mu_{t}}{\sigma_{k}}\right) \frac{\partial k}{\partial x_{j}}\right]}{\partial x_{j}}+G_{k}+G_{b}-\rho \varepsilon
$$

whereas the conservation of the dissipation of kinetic energy of turbulence is defined as:

$$
\begin{gathered}
\frac{\partial}{\partial x_{i}}\left(\rho \varepsilon u_{i}\right)=\frac{\partial}{\partial x_{j}}\left[\left(\mu+\frac{\mu_{t}}{\sigma_{\varepsilon}}\right) \frac{\partial \varepsilon}{\partial x_{j}}\right]+C_{1 \varepsilon} \frac{\varepsilon}{k}\left(G_{k}+G_{b}\right)-C_{2 \varepsilon} \rho \frac{\varepsilon^{2}}{k} \\
G_{k}=\mu_{t}\left(\frac{\partial u_{j}}{\partial x_{i}}+\frac{\partial u_{i}}{\partial x_{j}}\right) \frac{\partial u_{i}}{\partial x_{j}} \\
G_{b}=-g_{i} \frac{\mu_{t}}{\rho P r_{t}} \frac{\partial \rho}{\partial x_{i}}
\end{gathered}
$$

where $C_{1 \varepsilon}=1.44, C_{2 \varepsilon}=1.92, k=1.0$, and $\varepsilon=1.3$ are empirical constants; $P r_{t}$ is the turbulent Prandtl number; $G_{k}$ is the generation of turbulence kinetic energy due to the mean velocity gradients; and $G_{b}$ is the generator of turbulence kinetic energy due to buoyancy.

The equations provided above govern the continuous phase constituted by the argon carrier gas. To complete the theoretical basis of this CFD analysis, the equations governing the secondary phase have to be provided. The discrete phase representing the powder particles dispersed into the continuous phase is computed by ANSYS ${ }^{\circledR}$ FLUENT, which integrates the differential equation of a particle's force balance in a Lagrange coordinate system. The balance of the forces is given by:

$$
\frac{d u_{p, i}}{d t}=F_{D}\left(u-u_{p}\right)-g_{i}\left(\frac{\rho_{p}-\rho}{\rho_{p}}\right)+F_{i}
$$

where $u_{p}$ is the particle velocity, $u$ is the fluid phase velocity, $\rho$ is the fluid density, $\rho_{p}$ is the density of the particles, $g$ is the gravitational acceleration, and $F_{i}$ is an additional acceleration (force/unit particle mass) term. The $F_{D}$ coefficient is the drag force per powder mass unit and it can be calculated as:

$$
F_{D}=\frac{18 \mu}{\rho_{p} d_{p}^{2}} \frac{C_{D} R e}{24}
$$

In the equation defining $F_{D}, \mu$ is the molecular viscosity of the fluid, $d_{p}$ is the particle diameter, $R e$ is the relative Reynolds number, and $C_{D}$ is the drag coefficient, defined as:

$$
\begin{gathered}
R e=\frac{\rho d_{p}\left|u_{p}-u\right|}{\mu} \\
C_{D}=a_{1}+\frac{a_{2}}{R e}+\frac{a_{3}}{R e^{2}}
\end{gathered}
$$

where $a_{1}, a_{2}$, and $a_{3}$ are empirical constants. The second term on the right of Equation (8) consists of the gravity and buoyancy forces per unit particle mass. Therefore, the particle velocity can be acquired as:

$$
\frac{d x_{i}}{d t}=u_{p, i}
$$

The particle trajectory can be obtained using Equations (8) and (12).

The domain taken into account during the numerical simulation is composed by a control volume large enough to allow the complete development of the powder flow at the exit of the deposition nozzle. 
In the case of two active nozzles, a symmetry condition is assumed. The theoretical assumptions taken into account for the numerical analysis are:

- only the forces of drag, inertia, and gravity are included in the analysis;

- collisions among particles are not considered;

- the grain size distribution is considered uniform with an average diameter of $70 \mu \mathrm{m}$, since it corresponds to the mass median diameter of the powder particle distribution;

- the gas-powder flow is assumed to be a steady state flow;

- the powder particles are assumed to be spherical in shape;

- the substrate "traps" the powder particles reaching the surface.

\section{Results}

Table 2 summarizes the results concerning the $95 \%$ of the portion of the total powder flow width at $15 \mathrm{~mm}$ below the nozzle outlet for the two process conditions where the presence of the substrate is not taken into account (see Figure 3a,b). In the case of only one active nozzle (Figure 3a), the effects of the shielding gas ( $p$-value $=0.000)$ and of the powder feed rate $(p$-value $=0.001)$ are significant. Increasing the powder feed rate from 0.1 to $0.14 \mathrm{~g} / \mathrm{s}$, the $95 \%$ of the total spread of the powder flow at $15 \mathrm{~mm}$ decreases from 4.58 to $4.43 \mathrm{~mm}$ in average, obtaining an average absolute variation of $-9.8 \%$. This behaviour is significant and demonstrates the effectiveness of the suggested nozzle solution in the powder particle deposition, since it is capable of ensuring a high particle powder concentration focused at the centre of the flow, thus decreasing the width of the powder flow (i.e., the powder flow width at $15 \mathrm{~mm}$ from the nozzle outlet).

The influence of the shielding gas on the powder flow profile is consistent for every evaluated combination of process parameters and it is well represented in Figure 7. The external flow of inert gas compacts the powder particles at the exit of the nozzle and contrasts the effect of the gravity force that tends to pull down the powder particles, deflecting them from the nominal trajectory imposed by the nozzle geometry. Upon increasing the shielding mass flow rate from 0 to $2.92 \mathrm{e}^{-0.4} \mathrm{~kg} / \mathrm{s}$, the spread of the powder flow at $15 \mathrm{~mm}$ from the nozzle outlet decreases to about $-14.6 \%$ on average.

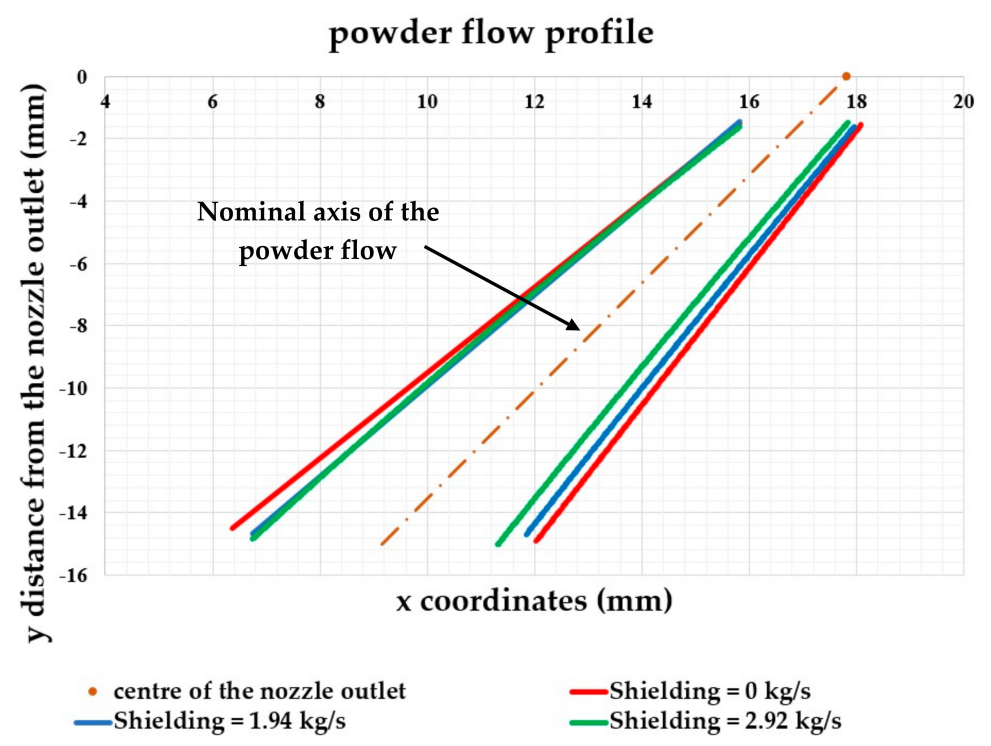

Figure 7. Influence of the shielding gas on the profile of the powder flow (one active nozzle). 
Table 2. Summary of the experimental results without the presence of the substrate.

\begin{tabular}{|c|c|c|c|c|c|c|c|c|}
\hline \multirow{3}{*}{ One Active Nozzle } & \multicolumn{4}{|c|}{ Powder Feed Rate $=0.1 \mathrm{~g} / \mathrm{s}$} & \multicolumn{4}{|c|}{ Powder Feed Rate $=0.14 \mathrm{~g} / \mathrm{s}$} \\
\hline & \multicolumn{2}{|c|}{ Carrier $=4.51 \mathrm{e}^{-0.5} \mathrm{~kg} / \mathrm{s}$} & \multicolumn{2}{|c|}{ Carrier $=5.41 \mathrm{e}^{-0.5} \mathrm{~kg} / \mathrm{s}$} & \multicolumn{2}{|c|}{ Carrier $=4.51 \mathrm{e}^{-0.5} \mathrm{~kg} / \mathrm{s}$} & \multicolumn{2}{|c|}{ Carrier $=5.41 \mathrm{e}^{-0.5} \mathrm{~kg} / \mathrm{s}$} \\
\hline & $95 \%$ Width (mm) & Variation (\%) & $95 \%$ Width (mm) & Variation (\%) & $95 \%$ Width (mm) & Variation (\%) & $95 \%$ Width (mm) & Variation (\%) \\
\hline Shielding $=0 \mathrm{~kg} / \mathrm{s}$ & 4.93 & - & 4.98 & - & 4.77 & - & 4.97 & - \\
\hline Shielding $=1.95 \mathrm{e}^{-0.4} \mathrm{~kg} / \mathrm{s}$ & 4.33 & -12 & 4.57 & -8.3 & 4.41 & -7.6 & 4.33 & -12.8 \\
\hline Shielding $=2.92 \mathrm{e}^{-0.4} \mathrm{~kg} / \mathrm{s}$ & 4.29 & -13 & 4.35 & -12.7 & 4.22 & -11.5 & 3.91 & -21.3 \\
\hline \multirow{3}{*}{ Two Active Nozzles } & \multicolumn{4}{|c|}{ Powder Feed Rate $=0.2 \mathrm{~g} / \mathrm{s}$} & \multicolumn{4}{|c|}{ Powder Feed Rate $=0.28 \mathrm{~g} / \mathrm{s}$} \\
\hline & \multicolumn{2}{|c|}{ Carrier $=9.02 \mathrm{e}^{-0.5} \mathrm{~kg} / \mathrm{s}$} & \multicolumn{2}{|c|}{ Carrier $=1.08 \mathrm{e}^{-0.4} \mathrm{~kg} / \mathrm{s}$} & \multicolumn{2}{|c|}{ Carrier $=9.02 \mathrm{e}^{-0.5} \mathrm{~kg} / \mathrm{s}$} & \multicolumn{2}{|c|}{ Carrier $=1.08 \mathrm{e}^{-0.4} \mathrm{~kg} / \mathrm{s}$} \\
\hline & $95 \%$ Width (mm) & Variation (\%) & $95 \%$ Width (mm) & Variation (\%) & $95 \%$ Width (mm) & Variation (\%) & $95 \%$ Width (mm) & Variation $(\%)$ \\
\hline Shielding $=0 \mathrm{~kg} / \mathrm{s}$ & 5.73 & - & 6.34 & - & 5.27 & - & 5.56 & - \\
\hline Shielding $=3.9 \mathrm{e}^{-0.4} \mathrm{~kg} / \mathrm{s}$ & 5.11 & -10.9 & 5.22 & -17.8 & 4.40 & -16.5 & 5.68 & -2.3 \\
\hline Shielding $=5.84 \mathrm{e}^{-0.4} \mathrm{~kg} / \mathrm{s}$ & 5.29 & -7.8 & 5.58 & -12.1 & 5.32 & -1.1 & 5.64 & -1.5 \\
\hline
\end{tabular}


In the case of two active nozzles without the presence of the substrate, analysis of variance (ANOVA) demonstrates that the powder feed rate has a negligible effect ( $p$-value $=0.064$ ) on the spread variation of the powder flow compared to the shielding ( $p$-value $=0.001$ ) and carrier gas $(p$-value $=0.000)$. Upon increasing the carrier gas from $9.02 \mathrm{e}^{-0.5}$ to $1.08 \mathrm{e}^{-0.4} \mathrm{~kg} / \mathrm{s}$, the spread of the powder flow increases (see Table 2). This is mainly due to the increase in the carrier inertia that limits the effect of the shielding gas. Moreover, the influence of the shielding gas is not linear, as happens in the process condition with only one active nozzle. In this case, the experimental analysis shows a significant reduction in the powder particles diffusions for medium values of the shielding gas, followed by a critical enlargement at the highest values. For medium values of the shielding gas, in fact, the average $95 \%$ of the powder flow width at $15 \mathrm{~mm}$ decreases down to $-11.8 \%$, whereas for higher mass flow rates the width only decreases down to $-5.6 \%$. The reason for this behaviour can be related to the location at which the two powder flows meet each other. Indeed, upon increasing the shielding mass flow rate from $3.9 \mathrm{e}^{-0.4} \mathrm{~kg} / \mathrm{s}$ to $5.84 \mathrm{e}^{-0.4} \mathrm{~kg} / \mathrm{s}$, the zone where the two powder flows meet each other ends up being lower compared to the previous cases, moving away from the nozzle outlet. This phenomenon affects the measurements since for high values of the shielding mass flow, the deposition plane is no longer located at $15 \mathrm{~mm}$ from the nozzle outlet.

Concerning the case of two active nozzles with the presence of the substrate at $15 \mathrm{~mm}$ from the nozzle outlet, the acquired images are strongly affected by a high concentration of bouncing powder particles that degrade the image analysis, making it impossible to define a reliable image intensity threshold and preventing the application of the image-based method previously discussed. For this reason, only a qualitative analysis is possible for comparing the different spectra of the powder particles distribution in correspondence to the surface of the substrate. Figure 8 illustrates the effect of the shielding gas for constant values of the carrier mass flow rate and the powder feed rate. In the case of no shielding (see Figure 8a), the area with the larger particle mass concentration (i.e., the red one) is wider compared with those represented in Figure $8 \mathrm{~b}, \mathrm{c}$, in which the shielding gas is $3.9 \mathrm{e}^{-0.4} \mathrm{~kg} / \mathrm{s}$ and $5.84 \mathrm{e}^{-0.4} \mathrm{~kg} / \mathrm{s}$, respectively. In particular, when no shielding is applied, the top edges of the area with the maximum powder concentration are indented, indicating a strong rebound of the powder particles on the metal surface of the substrate. On the contrary, Figure $8 b, c$ show a red area with more defined edges and then a limited rebound of the powder particles. The zone with the higher particle concentration seems to be qualitatively smaller for higher values of the shielding mass flow rate (see Figure 8c). Nevertheless, to have a feedback and a quantitative analysis of the influence of the shielding, carrier, and powder mass flow on the deposition efficiency of the process under this process conditions, further experimental tests are required.

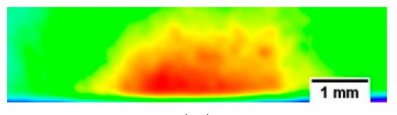

(a)

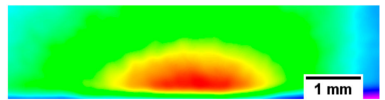

(b)

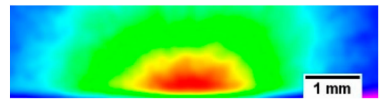

(c)

Figure 8. Two active nozzles with a substrate at $15 \mathrm{~mm}$. Carrier mass flow $=1.08 \mathrm{e}^{-0.4} \mathrm{~kg} / \mathrm{s}$, powder feed rate $=0.2 \mathrm{~g} / \mathrm{s}$ : (a) shielding $=0 \mathrm{~kg} / \mathrm{s}$; (b) shielding $=3.9 \mathrm{e}^{-0.4} \mathrm{~kg} / \mathrm{s}$; (c) shielding $=5.84 \mathrm{e}^{-0.4} \mathrm{~kg} / \mathrm{s}$.

\section{Discussion}

The CFD model is verified, estimating the spread of the powder flow at $15 \mathrm{~mm}$ from the nozzle outlet and taking into account the particle mass concentration (see Figure 9a). To correctly compare the numerical outputs with the experimental results, the nominal particle mass concentration is adequately filtered for each combination of process parameters, since:

- $\quad$ the experimental analysis is based on 2D images (as those reported in Figure 4);

- the employment of a "binary-mask" filter requires the application of an intensity threshold to highlight the shape of the powder flow;

- the particle mass concentration is provided by the numerical software with no filtering. 
The filtering threshold set to cut off the numerical outputs is equivalent in terms of percentages to the intensity threshold employed during the image analysis. After filtering, 10 lines are transversely traced to discretize the particle mass concentration and detect the spread of the powder flow at $15 \mathrm{~mm}$ from the nozzle outlet (as shown in Figure 9b). The numerical powder flow width to compare with the experimental one is estimated by computing the $95 \%$ of the total particle mass concentration resulting from the sum of the 10 tracked lines, cutting off the values lower than the $5 \%$ of the maximum powder concentration.
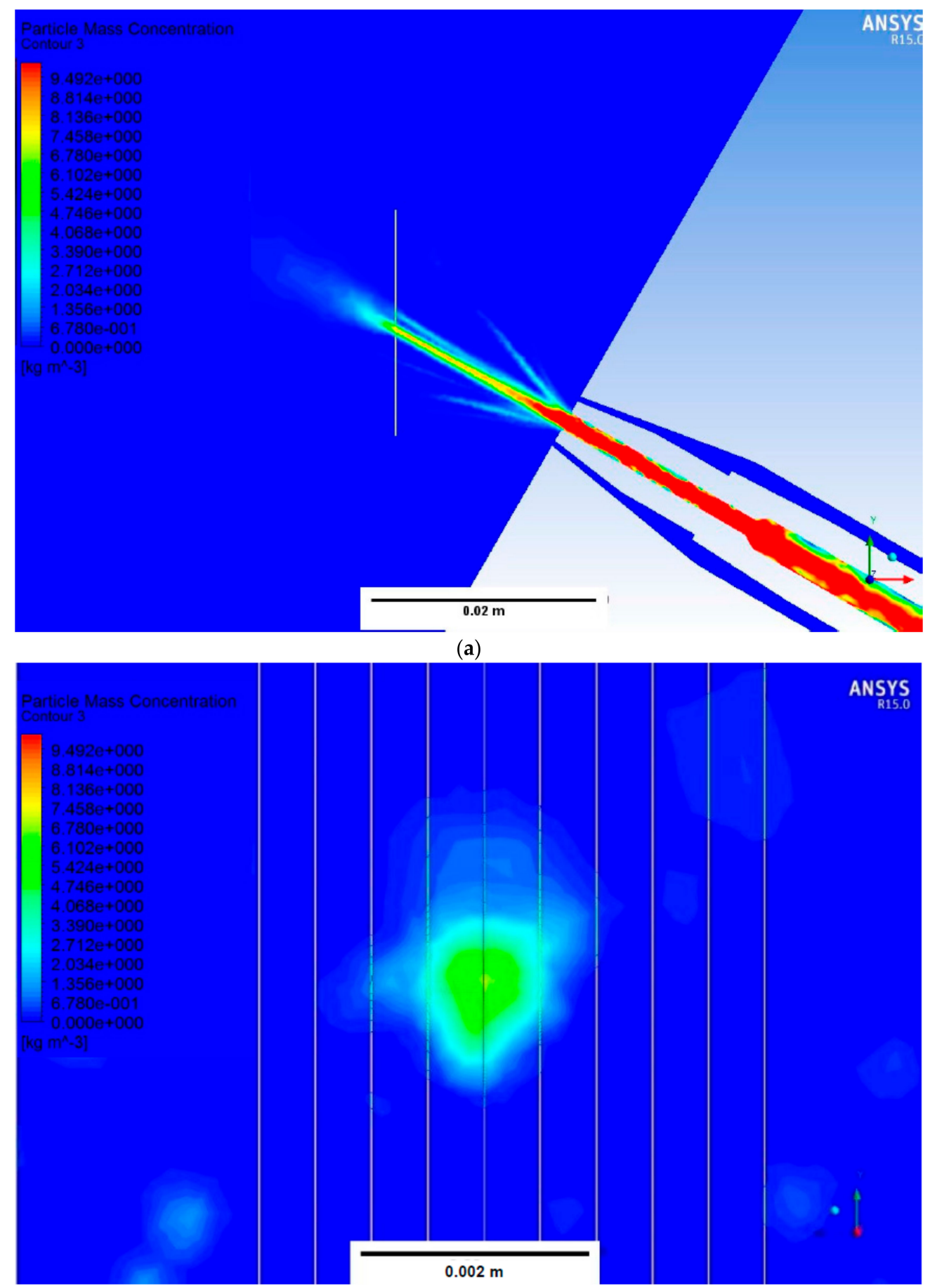

(b)

Figure 9. (a) Particle mass concentration along the nozzle axis; (b) particle mass concentration at the deposition plane and the 10 evaluation lines. 
The numerical results do not correspond to the experimental ones; from data reported in Table 3 it is possible to note that the estimated powder flow width is quite different from the results obtained by the experimental characterization.

Table 3. Comparison between experimental and numerical results.

\begin{tabular}{|c|c|c|c|}
\hline \multirow{3}{*}{ One Active Nozzle } & \multicolumn{3}{|c|}{ Powder Feed Rate $=0.1 \mathrm{~g} / \mathrm{s}$} \\
\hline & \multicolumn{3}{|c|}{ Carrier $=4.51 \mathrm{e}^{-0.5} \mathrm{~kg} / \mathrm{s}$} \\
\hline & Shielding $=0 \mathrm{~kg} / \mathrm{s}$ & Shielding $=1.95 \mathrm{e}^{-0.4} \mathrm{~kg} / \mathrm{s}$ & Shielding $=2.92 \mathrm{e}^{-0.4} \mathrm{~kg} / \mathrm{s}$ \\
\hline $\begin{array}{l}\text { Experimental } 95 \% \text { of the } \\
\text { total width }[\mathrm{mm}]\end{array}$ & 4.93 & 4.33 & 4.29 \\
\hline $\begin{array}{l}\text { Numerical } 95 \% \text { of the } \\
\text { total width }[\mathrm{mm}]\end{array}$ & 5.9 & 5.5 & 7.5 \\
\hline \multirow{3}{*}{ Two Active Nozzles } & \multicolumn{3}{|c|}{ Powder Feed Rate $=0.2 \mathrm{~g} / \mathrm{s}$} \\
\hline & \multicolumn{3}{|c|}{ Carrier $=9.02 \mathrm{e}^{-0.5} \mathrm{~kg} / \mathrm{s}$} \\
\hline & Shielding $=0 \mathrm{~kg} / \mathrm{s}$ & Shielding $=3.90 \mathrm{e}^{-0.4} \mathrm{~kg} / \mathrm{s}$ & Shielding $=5.84 \mathrm{e}^{-0.4} \mathrm{~kg} / \mathrm{s}$ \\
\hline $\begin{array}{l}\text { Experimental } 95 \% \text { of the } \\
\text { total width }[\mathrm{mm}]\end{array}$ & 5.73 & 5.11 & 5.29 \\
\hline $\begin{array}{l}\text { Numerical } 95 \% \text { of the } \\
\text { total width [mm] }\end{array}$ & 4.6 & 9.4 & 4.2 \\
\hline
\end{tabular}

For both one active nozzle and two active nozzles systems, the employed CFD model is not capable of correctly estimating the powder behaviour. From an analysis of the CFD results, for each combination of process parameters, the shielding gas seems to have a very low influence on the powder flow geometry (see Figure 10). Indeed, both in the case with no shielding (see Figure 10a) and in the case with shielding (see Figure 10b,c), the graphical CFD results show the presence of secondary isolated powder flows that diverge from the central main powder flow. These secondary flows seem to not be affected by the presence of the shielding that should deflect them or limit their extension.

The motivations for such different results could be attributed to two different reasons:

- the critical issue in the choice of the filtering value to apply to the CFD outputs;

- the inadequacy of the employed CFD model and assumptions.

The employment of a correct value to filter all the data provided by the CFD analysis is a critical issue not easy to deduce, but it is required to compare the numerical results with the experimental ones due to the application of a binary-mask filter during the experimental image analysis. Nevertheless, the numerical method employed in this analysis seems to not fit the behaviour of the powder flow recorded during the experimental investigation, probably because both the influence of the air at the exit of the deposition nozzle is not taken into account and the powder grain size distribution is not correctly estimable by its mass median diameter (i.e., $70 \mu \mathrm{m}$ ). To improve the CFD simulation and to obtain a powder flow behaviour more in compliance with the real one, a more complex model has to be taken into account, such as the Eulerian multiphase model. The Eulerian multiphase is a model implemented in ANSYS ${ }^{\circledR}$ FLUENT, which allows for the modeling of multiple separate, yet interacting phases, where Eulerian treatment is used for each phase, in contrast to the Eulerian-Lagrangian treatment that is used only for the discrete phase model. The application of this numerical model together with a more accurate estimation of the distribution of the powder grain size (i.e., Rosin-Rammler particle size distribution) could improve the experimental fitting of the powder behaviour at the expense of more computational time and memory. 


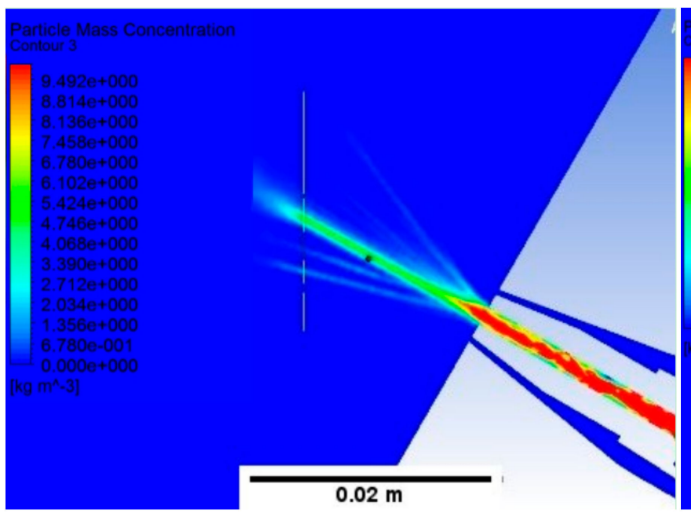

(a)

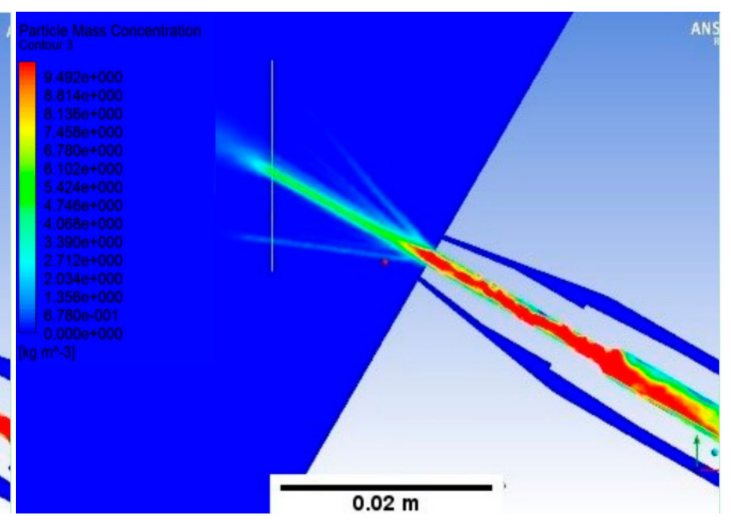

(b)

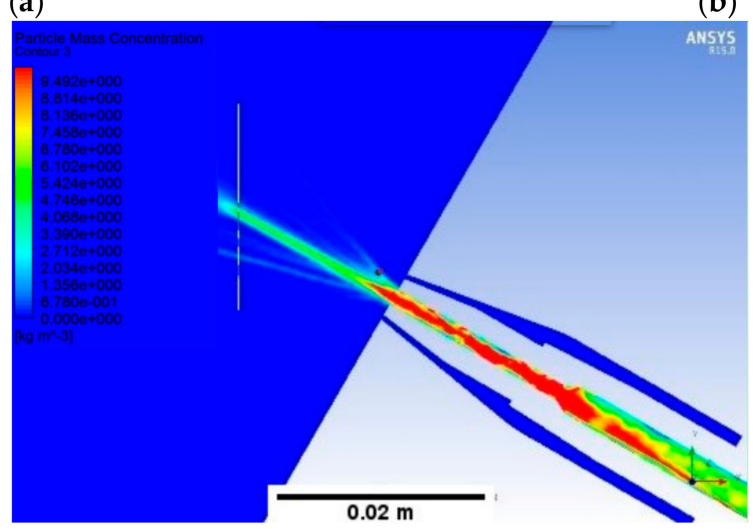

(c)

Figure 10. Carrier mass flow rate $=4.51 \mathrm{e}^{-0.5} \mathrm{~kg} / \mathrm{s}$ and powder feed rate $=0.1 \mathrm{~g} / \mathrm{s}$ : (a) shielding mass flow $=0 \mathrm{~kg} / \mathrm{s}$; (b) shielding mass flow $=1.95 \mathrm{e}^{-0.4} \mathrm{~kg} / \mathrm{s}$; (c) shielding mass flow $=2.92 \mathrm{e}^{-0.4} \mathrm{~kg} / \mathrm{s}$.

\section{Conclusions}

In order to optimize the process efficiency of a DED system, the performances of a new deposition nozzle solution designed at DTI of SUPSI (Manno- $\mathrm{CH}$ ) are monitored through a high-speed camera. The influence of the shielding mass flow rate, carrier mass flow rate, and powder feed rate on the shape of the powder flow at the exit of the nozzle outlet and the spread of the powder particles on the deposition plane is analysed. The main findings of the experimental investigation are:

- the solution of a shielding gas external to the carrier gas significantly affects the powder distribution and powder flow geometry, decreasing the powder spread in correspondence to the deposition plane;

- the external shielding gas contains the spread of the powder particles in opposition to the gravity force and carrier gas inertia that tend to enlarge the powder flow;

- in the case of one active nozzle, increasing the shielding mass flow rate up to $2.92 \mathrm{e}^{-0.4} \mathrm{~kg} / \mathrm{s}$ leads an average reduction of $-14.6 \%$ of the powder flow width in correspondence to the deposition plane;

- in the case of two active nozzles with the presence of the substrate, the shielding gas qualitatively seems to reduce the powder rebound, reducing the extension of the zone of higher particle concentration;

- the employed CFD model does not fit the experimental results. A new and more complex theoretical model has to be implemented to simulate the process (i.e., Eulerian multiphase model) providing a more reliable distribution of the powder grain size (i.e., Rosin-Rammler particle size distribution); 
- the results of the experimental campaign highlight that the analysed deposition nozzle can be a good solution for the improvement of the catchment efficiency of a DED system, reducing the powder spread in correspondence to the deposition plane.

Acknowledgments: The authors would like to acknowledge the European research project belonging to the Horizon 2020 research and innovation programme Borealis- the 3A energy class Flexible Machine for the new Additive and Subtractive Manufacturing on next generation of complex 3D metal parts.

Author Contributions: Federico Mazzucato, Mariangela Lombardi and Anna Valente conceived and designed the experiments; Federico Mazzucato performed the experiments; Federico Mazzucato, Simona Tusacciu and Anna Valente analyzed the data; Sara Biamino and Manuel Lai contributed to material selection; Federico Mazzucato, Sara Biamino and Mariangela Lombardi wrote the paper.

Conflicts of Interest: The authors declare no conflict of interest.

\section{References}

1. Dunsky, C. Process monitoring in laser additive manufacturing. Ind. Laser Solut. Manuf. 2014, 29, 14-20.

2. Sames, W.J.; List, F.A.; Pannala, S.; Dehoff, R.R.; Babu, S.S. The metallurgy and processing science of metal additive manufacturing. Int. Mater. Rev. 2016, 61, 315-360. [CrossRef]

3. Herzog, D.; Seyda, V.; Wycisk, E.; Emmelmann, C. Additive manufacturing of metals. Acta Mater. 2016, 117, 371-392. [CrossRef]

4. Scott, J.; Gupta, N.; Weber, C.; Newsome, S.; Wohlers, T.; Caffrey, T. Additive Manufacturing: Status and Opportunities; Science and Technology Policy Institute: Washington, DC, USA, 2012; pp. 1-29.

5. Toyserkani, E.; Khajepour, A.; Corbin, S.F. Laser Cladding; CRC Press: Boca Raton, FL, USA, 2004.

6. Zekovic, S.; Dwivedi, R.; Kovacevic, R. Numerical simulation and experimental investigation of gas-powder flow from radially symmetrical nozzles in laser-based direct metal deposition. Int. J. Mach. Tools Manuf. 2007, 47, 112-123. [CrossRef]

7. Ding, Y.; Dwivedi, R.; Kovacevic, R. Process planning for 8-axis robotized laser-based direct metal deposition system: A case on building revolved part. Robot. Comput. Integr. Manuf. 2017, 44, 67-76. [CrossRef]

8. Fessler, J.R.; Merz, R.; Nickel, A.H.; Prinz, F.B. Laser deposition of metals for shape deposition manufacturing. In Solid Freeform Fabrication Symposium; Bourell, D., Beaman, J., Marcus, H., Crawford, R., Barlow, J., Eds.; University of Texas at Austin: Austin, TX, USA, 2017.

9. Thompson, S.T.; Bian, L.; Shamsaei, N.; Yadollahi, A. An overview of Direct Laser Deposition for additive manufacturing; Part I: Transport phenomena, modelling and diagnostics. Add. Manuf. 2015, 8, 36-62. [CrossRef]

10. Balu, P.; Leggett, P.; Kovacevic, R. Parametric study on a coaxial multi-material powder flow in laser-based powder deposition process. J. Mater. Process. Technol. 2012, 212, 1598-1610. [CrossRef]

11. Zhu, G.; Li, D.; Zhang, A.; Tang, Y. Numerical simulation of metallic powder flow in a coaxial nozzle in laser direct metal deposition. Opt. Laser Technol. 2011, 43, 106-113. [CrossRef]

12. Smurov, J.; Doubenskaia, M.; Zaitsev, A. Comprehensive analysis of laser cladding by means of optical diagnostics and numerical simulation. Surf. Coat. Technol. 2013, 220, 112-121. [CrossRef]

13. Kovaleva, I.; Kovalev, O.; Zaitsev, A.; Smurov, I. Numerical simulation and comparison of powder jet profiles for different types of coaxial nozzles in direct material deposition. Phys. Procedia 2013, 41, 810-872. [CrossRef]

14. Costa, L.; Vilar, R. Laser powder deposition. Rapid Prototyp. J. 2009, 15, 264-279. [CrossRef]

15. Song, L.; Bagavath-Singh, V.; Dutta, B.; Mazumder, J. Control of melt pool temperature and deposition height during direct metal deposition process. Int. J. Adv. Manuf. Technol. 2012, 58, 247-256. [CrossRef]

16. Tabernero, I.; Lamikiz, A.; Ukar, E.; Lopez de Lacalle, L.N.; Angulo, C.; Urbikain, G. Numerical simulation and experimental validation of powder flux distribution in coaxial laser cladding. J. Mater. Process. Technol. 2010, 210, 2125-2134. [CrossRef]

17. Wen, S.Y.; Shin, Y.C.; Murthy, J.Y.; Sojka, P.E. Modeling of coaxial powder flow for the laser direct deposition process. Int. J. Heat Mass Transf. 2009, 52, 5867-5877. [CrossRef]

18. ImageJ v1.51k. Available online: https://imagej.nih.gov/ij/ (accessed on 26 May 2017).

(C) 2017 by the authors. Licensee MDPI, Basel, Switzerland. This article is an open access article distributed under the terms and conditions of the Creative Commons Attribution (CC BY) license (http://creativecommons.org/licenses/by/4.0/). 